\title{
Investigation into the Filterability of Raw Sugars from Different Geographical Regions of the World
}

\author{
Kamal Suleiman Hassan ${ }^{1}$, Kanada Toto Korea ${ }^{2}$, Abubakr Musa ${ }^{1,3, *}$ \\ ${ }^{1}$ Sugar Institute, University of Gezira, Wad Madani, Algezira, Sudan \\ ${ }^{2}$ Alkhaleej Sugar Co., Dubai, UAE \\ ${ }^{3}$ School of Food and Biological Engineering, Jiangsu University, Zhenjiang, China
}

Email address:

abmuah@hotmail.com (A. Musa)

*Corresponding author

\section{To cite this article:}

Kamal Suleiman Hassan, Kanada Toto Korea, Abubakr Musa. Investigation into the Filterability of Raw Sugars from Different Geographical Regions of the World. International Journal of Computational and Theoretical Chemistry. Vol. 5, No. 6, 2017, pp. 53-58. doi: $10.11648 /$ j.ijctc. 20170506.11

Received: October 19, 2017; Accepted: November 8, 2017; Published: January 2, 2018

\begin{abstract}
This study was carried out at Alkhaleej Sugar Refinery in Dubai, United Arab Emirates. The study aimed to find out the correlation between the filterability and slurry resistance value so fraw meltliquor in the carbonation sugar refinery and the raw sugar quality. The investigation utilized 5 raw sugar samples originated from various regions of the world comprising three quality groups namely; low pol sugar (LP) originated from Thailand, very high pol sugar (VHP) originated from Brazil, South-Africa, Sudan, India, and very high pol sugar (VVHP) originated from Brazil. The filterability and the slurry resistance tests were used as the main determining factors for the evaluation. The filterability of refined sugar (consideredas $100 \%$ ) was used as a reference value for comparison. The results of the experiments showed that the filterability of low pol raw sugar was only about $20 \%$ from that of refined sugar. Whereas the filterability values for VHP and VVHP sugars ranged between $40 \%$ to $80 \%$ from that of refined sugar. In addition, the slurry resistance values for VHP and VVHP sugars in the laboratory were 0.76 and 0.64 respectively compared to 0.74 and 0.48 in the refinery production line. It was also observed that there is a close similarity between laboratory filterability and slurry resistance with the actual refinery filtration process swhich suggests that the laboratory filterability and slurry resistance tests could be used as tool to predict the behavior of the refinery filtration process for similar qualities of raw sugar.
\end{abstract}

Keywords: Raw Sugar, Refinery, Filterability, Slurry Resistance

\section{Introduction}

Filtration process is an old well-established unit operation which is traced back to 1789 . It is used in sugar refining industry to remove the suspended non-sugar particles from the melted raw liquor after the purification stage [1]

Clarke [2], stated that the knowledge of the composition of raw sugar is essential in order to optimize the refinery operations and the selection of suitable methods of purification for the efficient removal of nonsugar components.

Raw meltliquor purification can be effected either by carbonation process or phosphotation process. During these processes most of the impurities are precipitated either in the form of calcium carbonate from carbonatation refinery or calcium phosphate from phosphatation refinery.

The nonsucrose content of raw sugar has been studied by many research workers [3, 4]. They stated that the nonsucrose content of the raw sugar is different from one country to another, qualitatively and quantitatively.

The efficiency of each stage of the refining process is influenced in different ways by the quality of raw sugar and depending on the type of refinery, its clarification and decolorization processes, some components are easy to remove, and others are more difficult.

Raw sugars from various regions of the world filter differently; though they might be from the same quality 
brand. Some filter well and others give poor filterability. The reasons are normally correlated to the specific quality characteristics of the sugar.

Filterability is defined as the ability of raw sugar to filter easily. It is an indication of the filtering characteristics of a raw sugar when it is processed through the clarification stage of the refinery.

No single factor that would impact on raw sugar filterability, but rather a combination of several factors. However, the parameters correlating most strongly with poor filterability are: turbidity, soluble phosphate, starch, suspended solids and dextran.

There are three major brands of the raw sugar; low polarization abbreviated as (LP) with Pol $<99 \%$, very high polarization (VHP) with Pol $99.3 \%$, and very very high polarization (VVHP) with Pol about $99.65 \%$ [5].

Raw sugars with poor filterabilities will be directly reflected in the refinery capacity. The liquor flow rates will be reduced due to difficulty infiltration. Hence, the operating personnel will find themselves forced to choose one of the following remedies:

1. Reduce the liquor brix which will lead to more consumption of steam at the evaporators to remove this water.
2. Increase the temperature of the liquor in order to reduce the viscosity, hence boosting the flow rates.

3. Add more alpha amylase enzyme when raw sugar is having high level of starch.

4. Increase lime ratio to give better purification performance and act as filter aid for filtration.

5. Add additional filter aid to reduce the insoluble solids and the turbidity levels of the filtrate.

There are two main parameters which are used as indicators for the evaluation of raw sugar filterability:

1. The (\%) filterability.

2. The slurry resistance.

Both indicators are very important criteria to be used for predicting the behavior of raw meltliquor at the filtration station of the sugar refinery.

Filterability in (\%) is defined as: the cumulative volumetric flow rate $(\mathrm{ml})$ of filtrate collected from filtering raw meltliquor at 65 Brix at $8.2 \mathrm{pH}$ and $80 \mathrm{C}-85 \mathrm{C}$ temperature through a pre-coated filter paper of (8microns) in 10minutes; divided by the flow rate of a pure refined sugar solution with similar conditions [6].

The slurry resistance of the formed cake was calculated using the following formula [7]:

$$
\text { Slurry Resistance }\left(\text { S. R) }=\frac{\text { Slope of linear line } \times 9.8 \times 10^{\wedge} 5}{\text { Brix }^{\wedge} 2 \times \text { density }^{\wedge} 2}\right.
$$

A graph of (filtration time of treated raw meltliquor divided by accumulated volume of filtrate versus accumulated volume of filtrate during that time) was plotted for each sugar sample and the slope of the linear line was calculated, then the slurry resistance value. The filtration time in this test was 10 minutes.

\section{Material and Methods}

\subsection{Materials}

The chemical reagents used in the experiments were prepared according to the international commission of uniform methods of sugar analysis (ICUMSA) methods [8].

Distilled water with a conductivity ash less than $2 \mu \mathrm{S} / \mathrm{cm}$ was used as the solvent for preparation of sugar solutions, and for preparing chemical reagents. There agents used in the experiments of filterability determination included:

1. Buffer solution: $\mathrm{pH} 9$.

2. Milk of lime solution: of 15 degree Baume.

3. Filter aid: Celite-505, Hyflosupercel.

4. Filter paper: 8 microns, and 0.45 micron filter papers.

\subsection{Methods of Analysis}

\subsubsection{Determination of the Filterability of Raw Sugar} Samples using Laboratory Filtration Equipment

This method is the modified Australian Nicholson Horsely filtration determination method [9]. It is based on the comparison between the volumes of filtrate of the test based on the comparison between the volume offiltrate of the test solutions of various raw sugars with the volume of filtrate of a pure white sugar solution under standard and identical conditions.

The calibration test performed using pure refined sugar was firstly done, and the volume of the filtrate was collected after 5 minutes and used as the reference to calculate the filterability of different test samples.

Procedure: a sample solution for each raw sugar was prepared and adjusted to 65.0 brix in aplastic bottle. The $\mathrm{pH}$ of the solution was adjusted to $\mathrm{pH} 8.2$ using buffer solution 9. The filter aid $\mathrm{C}$ elite Hyflosupercel was added $(0.5 \%$ on solids). The mixture was stoppered and heated in a water bath till $80^{\circ} \mathrm{C}$ with gentle shaking. The filtration apparatus was assembled and mounted in a water jacket. Water was circulated in the jacket and maintained at $80^{\circ} \mathrm{C}$. The sample was transferred to the filter funnel having 8 micron filter paper and the stopwatch was simultaneously started. The filtrate volume for each sample was collected after 5 minutes in a measuring cylinder for the calculation of filterability. The accumulated filtrate volumes against filtration time was recorded for 10 minutes. Finally a graph was plotted using the accumulated filtrate volume versus the filtration time.

For standardization, a pure refined sugar solution was prepared and adjusted to 65 brix, and the same procedure for filtering raw sugar samples was followed.

The volume of filtrate collected after 5 minutes was recorded. The filterability of each raw sugar sample was calculated against the refined sugar volume.

Calculations:

The filterability of each raw sugar sample was calculated using the formula: 
$\%$ Filterability $=\frac{\text { Vol of filtrate of the test solution } \times 100}{\text { Vol of filtrate of the pure sugar solution }}$

\subsubsection{Determination of Slurry Resistance for the Carbonated Liquor from Raw Sugar Samples in the Laboratory}

This method depends on performing a batch carbonatation process in the laboratory using laboratory filterability determination equipment [10].

Procedure: a solution of each raw sugar sample was prepared and adjusted to 65.0 brix in a 4 liters conical flask. The $\mathrm{pH}$ of the solution was adjusted to10.2 using milk of lime. The temperature of the solution was maintained at $80^{\circ} \mathrm{C}$ in a thermostatically controlled water bath. $\mathrm{CO}_{2}$ gas was bubbled in to the conical flask. The solution was kept in a gentle stirring till the final $\mathrm{pH}$ was 8.2. Then the filterability and slurry resistance of the formed carbonated liquor were obtained from the graph plotted between the accumulated filtrate volume versus the ratio of filtration time / accumulated volume.

The slurry resistance was calculated using the flowing formula [7]:

Slurry Resistance (S. R) $=\frac{\text { Slope of linear line } \times 9.8 \times 10^{5}}{\operatorname{Brix}^{\Lambda} 2 \times \text { density }^{\Lambda} 2}$

\subsubsection{Determination of the Filterability of Actual Refinery Carbonated Liquor Samples from VHP and VVHP Raw Sugars}

For the determination of the filterability of actual refinery liquor, $50 \mathrm{ml}$ of the carbonated liquor samples were collected from the carbonated liquor tank just before the filtration process on 2-hourly basis. Those samples were composted every 24 hours, and then heated to $80^{\circ} \mathrm{C}$. The brix and $\mathrm{pH}$ were measured. Finally the sample was analyzed for the filterability determination using similar procedure as for the raw sugar samples [9].

This procedure was followed with two different raw sugars namely, VHP and VVHP. Those analysis for the filterability were tripled for each type of raw sugar and the test results were averaged.

The four raw sugar samples were collected from traceability store of AlKhaleej Sugar Refinery laboratory. Those samples were from raw sugar ships received from; Brazil, India, Thailand, and South-africa. Also one sample from Kenana sugar factory-Sudan collected from the crop: 2007/2008.

Those samples were given designations as below:

1. sugar from Thailand was designated as (A).

2. sugar from Brazil was designated as (B).

3. sugar from South-Africa was designated as (C).

4. sugar from India was designated as (D).

5. sugar from Sudan was designated as (E).

Treated meltliquors from all sugar samples were undergone filterability test determination using laboratory filtration unit. Then the results of the determinations were presented in table 1, and graphically in figure 2.
Table 1. Results of Filterability test ( $\mathrm{ml} / 10 \mathrm{mins}$ ) for the five Raw Sugar Samples under Investigation.

\begin{tabular}{llllll}
\hline $\begin{array}{l}\text { Time } \\
\text { (Mins) }\end{array}$ & A & Raw & Sugar & Samples & \\
\cline { 2 - 6 } & B & C & D & E \\
\hline 1 & 10 & 28 & 24 & 12 & 16 \\
2 & 13 & 47 & 34 & 17 & 30 \\
3 & 16 & 54 & 41 & 21 & 38 \\
4 & 18 & 60 & 45 & 25 & 45 \\
5 & 20 & 65 & 48 & 28 & 52 \\
6 & 22 & 68 & 50 & 30 & 57 \\
7 & 23 & 71 & 52 & 32 & 60 \\
8 & 24 & 73 & 54 & 33 & 63 \\
9 & 25 & 75 & 55 & 33 & 65 \\
10 & 25 & 76 & 56 & 34 & 67 \\
\hline
\end{tabular}

Further, the slurry resistance of each treated liquor sample was calculated using the formula in the introduction.

\section{Results}

\subsection{Filterability}

Table 1 shows the results of filterability determination for all the five raw sugar samples.

Sugar (A) is a low polarization sugar. Logically, it gave the least volume of filtrate in 10 minutes; which is a clear evidence for being of poor filterability at the filtration station of the refinery.

Sugars (B, C, D, and E) are very high polarization sugars. By comparison, sugar-B gave the highest volume of filtrate in10 minutes, which is an indication for very good filterability at the filtration station of the refinery. Whereas, Sugar-D gave the least volume of filtrate in 10 minutes; indicating that it is of poor filtration behavior among the same quality brand of sugars.

The graphical representation for the filterability of all the sugar samples under investigation is demonstrated in Figure 1.

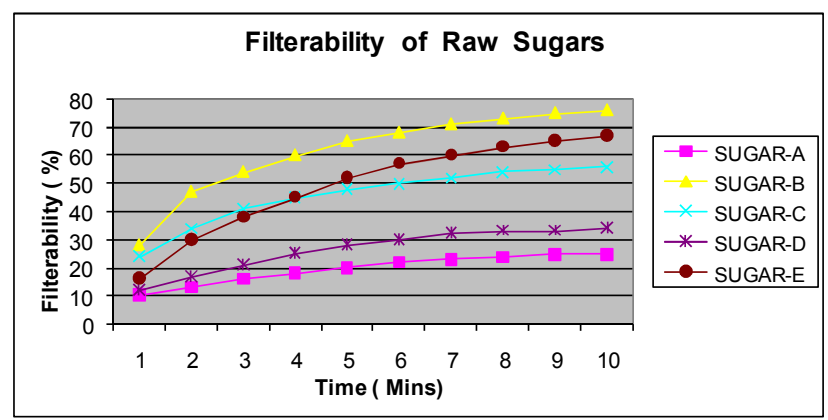

Figure 1. Filterability of raw sugar samples from various regions of the world.

\subsection{Slurry Resistance}

The slurry resistance values of the five raw sugar samples under investigation were calculated and shown in table 2. 
Table 2. Slurry Resistance Values for Raw Sugar Samples.

\begin{tabular}{lll}
\hline Sugar sample & Slurry resistance & Remarks \\
\hline A & 7.76 & The worst filterable \\
B & 0.82 & \\
C & 1.83 & \\
D & 3.53 & The best filterable \\
E & 0.70 & \\
\hline
\end{tabular}

It is obviously shown that sugar-A gave the highest slurry resistance value, whereas sugar-E gave the lowest slurry resistance value.

Comparing sugars $(\mathrm{B}, \mathrm{C}, \mathrm{D}$ and $\mathrm{E})$ which are of the same quality group of VHP, sugar-E unexpectedly gave the lowest slurry resistance value; in other words, the best filterable sugar. However, sugar-B was the one gave the highest filterability. This situation showed some contradiction between the filterability and the slurry resistance value. The possible reason could be due to the starch content of sugar-E which is the lowest among all the VHP sugars. Starch has a drastic impact on calcium carbonate crystals which affects filtration.

Filterability Determination Results of Actual Refinery Carbonated Liquor from VHP \& VVHP Sugars:

Samples of carbonated liquor just before the filtration process were collected 2-hourly at different occasions; when the refinery was processing VHP and VVHP sugars. The total collected samples from each sugar were composited every 24-hours, then analysed for the filterability values.

The results of the filterability determination for those refinery liquor samples are presented in Table 3. It is clear from this table that the filterability value of the carbonated liquor from VHP sugar was $54 \mathrm{ml}$ in 5 minutes. Whereas, the filterability value for the carbonated liquor from VVHP sugar was $76 \mathrm{ml}$ for the same period of time.

The graphical representation for the filterability y of actual refinery carbonated liquor from VHP and VVHP sugars is depicted in Figures 2 and 3 respectively. The filterability in both graphs is proportional with the increase in time.

Table 3. Results of filterability determination for the actual refinery carbonated liquor from VHP and VVHP sugars.

\begin{tabular}{lll}
\hline \multirow{2}{*}{ Time (mins) } & \multicolumn{2}{l}{ Carbonated Liquor $(\mathbf{m l})$} \\
\cline { 2 - 3 } & VHP & VVHP \\
\hline 1 & 22 & 32 \\
2 & 32 & 47 \\
3 & 41 & 59 \\
4 & 48 & 68 \\
5 & 54 & 76 \\
6 & 60 & 80 \\
7 & 64 & 87 \\
8 & 66 & 93 \\
9 & 69 & 98 \\
10 & 70 & 102 \\
\hline
\end{tabular}

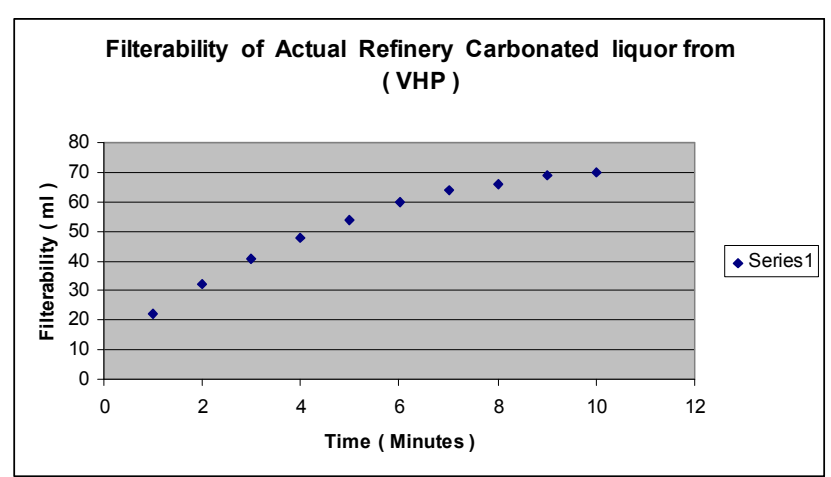

Figure 2. Filterability for actual refinery carbonated liquor from VHP sugar.

The slurry resistance values for the actual refinery carbonated liquor from VHP and VVHP sugars were presented in Table 4. Those values fall within the optimum range of (1 to 5) as specified by [7] for a good filtering raw sugar in Australia.

Table 4. Slurry Resistance Values of the actual refinery carbonated liquors from VHP and VVHP sugars.

\begin{tabular}{ll}
\hline Carbonated Liquor from & Slurry Resistance Value \\
\hline VHP Sugar & 0.74 \\
VVHP Sugar & 0.41 \\
\hline
\end{tabular}

\section{Discussion}

\subsection{Filterability of Raw Sugar Samples in the Laboratory}

Sugar sample-E, which belongs to raw sugar quality group of VVHP gave an excellent filterability; with the value almost similar to the value obtained from white sugar filterability. Such type of sugar is expected to give no problem during the filtration process of the refinery, and all the unit operations will be functioning well with maximum capacity and high efficiency.

On contrary, sugar sample-A, which belongs to raw sugar quality group of LP, showed a very poor filterability. With the value of $20 \%$ from white sugar filterability. Similar type of sugars are expected to experience poor filtration rates, hence reduction in plant capacity and limited outputs. The average filterability value for sugars $\mathrm{B}, \mathrm{C}$, and $\mathrm{E}$ was $55 \%$. Those sugars belong to raw sugar quality group of VHP. They are expected to show moderate filtration behavior with good flow rates.

Surprisingly, sugar sample-D which is a VHP raw sugar, gave the filterability value of only $28 \%$ from white sugar filterability. This value is very close to the filterability of sugar sample-A which is a low pol (LP). This indicates that raw sugars from different quality groups may filter in the similar manner depending on the effect to quality parameters contributing to the filtration impedance.

Those results were in agreement with the findings of [11] who stated that the filterability of low quality raw sugar will approach to $0 \%$, whereas the filterability of high quality raw sugar will approach to $100 \%$. 


\subsection{The Prediction of Raw Sugar Filterability Behavior During the Actual Refinery Filtration Process}

For a better comparison, the laboratory filterability test conditions were kept identical to the actual refinery filtration process conditions. This was very important in order to correlate the laboratory results to the refinery performance. The main difference was that laboratory test was batch process whereas the filtration process in the refinery was continuous.

Figures (2) and (3) indicate the graphical representation for the actual refinery carbonated liquor filtration of VHP and VVHP sugars respectively. The filterability value of the carbonated liquor when processing VHP sugar was $70 \mathrm{ml}$ in 10 minutes, against $102 \mathrm{ml}$ when processing VVHP sugar. This is the typical refinery filtration results after the carbonation process when the liquor is being filtered using pressure filters coated with the precipitated calcium carbonate obtained from the carbonation process to act as filteraid.

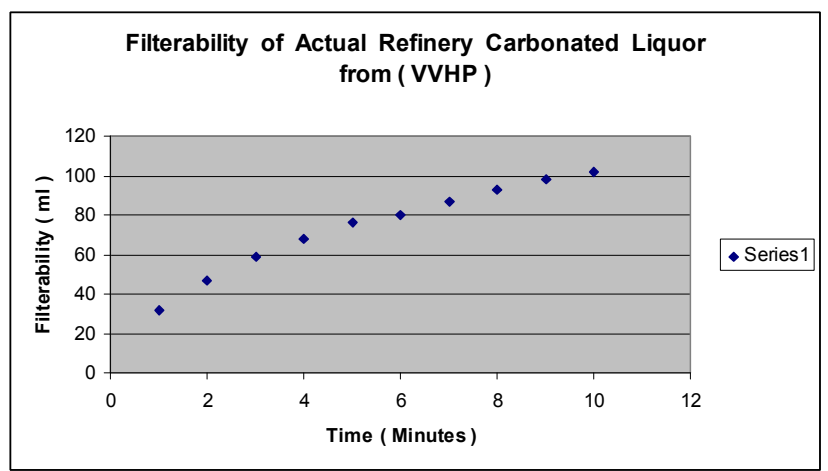

Figure3. Filterability for actual refinery carbonated liquor from VVHP sugar.

The average filterability value of carbonated liquor from VHP sugars obtained from laboratory tests was $66 \mathrm{ml}$ in 10 minutes. This value is almost similar to that of actual refinery filtration process $(70 \mathrm{ml} / 10 \mathrm{mins})$ indicated in Table 3.

Likewise, the filterability value for carbonated liquor obtained in the laboratory from VVHP sugar was $98 \mathrm{ml}$ in 10 minutes which is also almost coinciding with the value 102 $\mathrm{ml}$ of the actual refinery filtration process. Those results and their graphical representation indicate clear similarity between the laboratory filterability values and the correspondent values of carbonated liquors obtained from the similar qualities of raw sugar in the actual carbonation refinery filtration process.

The main reason is possibly attributed to the cumulative effect of raw sugar quality parameters in each quality group and their impact on the filterability.

These findings coincide with the previous studies made by $[12,13]$.

All of them agreed that the filterability test done in the laboratory scale can be used to predict the filtration process performance of a carbonatation refinery, in particular when the starch threshold level in raw sugar is lower than $200 \mathrm{ppm}$.

\subsection{The Prediction of Slurry Resistance Values for Carbonated Liquors During Refining Process}

The average value for slurry resistance of carbonated liquor from VHP sugars in the laboratory was (0.76), whereas for the similar quality of raw sugar in the actual refinery filtration process was $(0.74)$. These two values are almost the same.

Interestingly, sugar-D which is belonging to the quality group of VHP has differently with the slurry resistance value (3.53). This value is quite high for this group, rather it is closer to the group of low polarization (LP) raw sugars. It has the highest value of phosphatean ditsturbidity value is ranked as the second highest.

In the case of carbonated liquor from VVHP sugar, the slurry resistance value obtained in the laboratory was $(0.61)$, against $(0.41)$ for the actual refinery carbonation. This value is slightly higher than the refinery value. The slurry resistance values of carbonated liquors from VHP and VVHP sugars are quite similar to the actual refinery filtration process.

The average value for slurry resistance of carbonated liquor from VHP sugars in the laboratory was (0.76), whereas for the similar quality of raw sugar in the actual refinery filtration process for the actual refinery carbonation. This value is slightly higher than the refinery value, Tables 2 and 4. The slurry resistance values of carbonated liquors from VHP and VVHP sugars that the laboratory results are quite similar to the actual refinery filtration process.

\section{Conclusions}

The filterability and slurry resistance values fo raw sugar samples produced in Thailand, Brazil, South-Africa, India, and Sudan were determined using laboratory filtration apparatus. Interpretation of results obtained from those determinations allow to give conclusions that, raw sugars from the same quality brand may have different filtering behavior depending on the component influence of their quality parameters. SugarA produced in Thailand and falling under the raw sugar quality brand of low polarization (LP) showed a very poor filtrability. These results are reasonable for low pol sugar and definitely affect the filtration process. Sugar B, produced in Brazil gave the highest filterability value compared with other sugars from the same quality brand of (VHP). Whereas, sugar-D produced in India gave the lowest filterability value. Sugar-E, produced in Sudan gave the lowest value (0.70) of slurry resistance among the VHP sugars. However, it is ranked No.2 as the best filterable sugar. The geographical region did not show clear influence on the filterability of raw sugars produced at that area. Rather, the major parameters concentration with in the quality brand was the principal factor determining the filterability.

\section{References}

[1] Orr, C. (1977). Filtration Principles and Practices, 2nd. ed, Marcel Dekker, New York. 
[2] Clarke, S. J. (2000). Refining Quality of Raw Sugar. Handbook of Sugar Refining by Chou, pp: 607-626.

[3] Chou, C. C. (1991). Proceedings of Philiphines Sugar Technologists conference.

[4] Siato et al (1976). JSRT, vol (26), pp: 2043-2055.

[5] Rein, P., (2007). Cane Sugar Engineering, Bartens KG-Berlin.

[6] Winn, S. J. F (1979). Sugar Industry Technologists, Filterability, PP: 146-158.

[7] Field. J. P (2001). Technical Report to AKS on Filterability.

[8] ICUMSA, International Commission for Uniform Methods of Sugar Analysis, book (1994) with $1^{\text {st }}$ supplentm (1998). Colney, Norwich, England.
[9] Laboratory Manual for Australian sugar Mills (1984), Vol. 1.

[10] Lee, E. F. T and Donovan, M. (1996) Effect of Starch on Filterability of Carbonated Liquor, Proceedings of the 1996 Sugar Processing Research Conference (SPRC), New Orleans, Lousina, USA.

[11] Hidi, P., and Mc Cowage, R. J. (1984). Quantification of the Effects of Different Raw Sugar Impurities on Filtration Ratesin Carbonatation Refineries Proc. sugar process research, pp: 186-208.

[12] King, S., (2005). Raw Cane Sugar Quality from The Producer Perspective, Sugar International Technologists Conference, Dubai.

[13] Simpson, R., and Davis, S. B. (1998) Investigation in to the Filtering Quality of Raw Sugar, Proc. S. Afr. Sugar Technologist Ass. PP: 242-248. 